few familiar exampl returning to a marin

:re: mammals nabitat did so without re-evolving rills; hominids coming back down from the trees did not re-evolve non-primate characters; and birds returning to the ground have not been endued again with dinosaurian characters. Indeed, what is rare is a concise example of reversible evolution.

Department of Chemistry,

Patrick L. Williams

Northern Illinois University,

Dekalb, Illinois 60115, USA

\section{Nuclear risk evaluation}

SIR-Risk analyses by designers of large risky projects, such as nuclear reactors, calculate the probabilities of accidents with the help of a decision tree, and the likelihood of the failures of each component or safety system is assessed ${ }^{1}$. The results are the inputs for a chain of calculations leading to probabilistic risk assess ment. The unreliability of the method is well known. Accidents of nuclear power plants that were considered by their designers to have a risk of occurring once in a million years have happened twice in a decade, or less than 10,000 factoryoperating years ${ }^{2}$. A comparison of the observed failure frequency of civil engineering is several orders of magnitude greater than the safety to be expected from calculations ${ }^{3}$. Therefore, the technical risk assessment used to calculate nuclear safety must be replaced by an assessment which uses data from operating experiences ${ }^{4}$.

Previous efforts to use observational data to assess nuclear risks made use of only two data points, the Three Mile Island and Chernobyl accidents, assuming that the accidents are Poisson processes ${ }^{4}$. The reliability of a statistical method depends upon the availability of sufficient observational data, and because there have been few accidents at nuclear power plants, the usefulness of a statistical method has been questioned ${ }^{3}$. The impasse in the statistical approach results from the fact that the data on smaller accidents or incidents have been dismissed; minor incidents have been considered irrelevant because they did not do much damage.

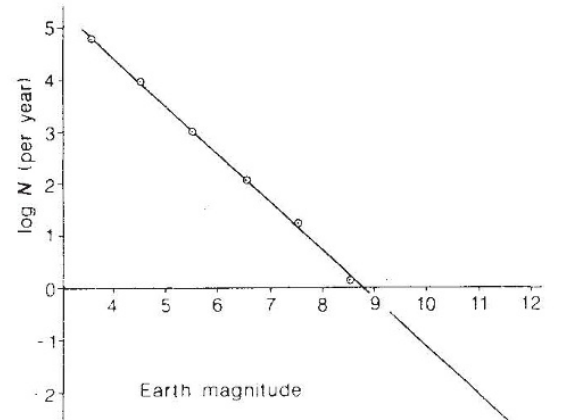

Fig. 1 Earthquake frequency-magnitude plot ${ }^{\star}$.
Studying natural catastrophes in history, such as landslides, submarine avalanches, earthquakes, desiccation of a marine basin (up to the size of the Mediterranean Sea), and of meteorite impact, I observed a linear relationship between the magnitude and frequency of the events when these parameters are plotted on log$\log$ graph paper. ${ }^{5}$. This relationship has recently been confirmed by statistical studies between crater sizes and impact frequencies ${ }^{6}$. The inverse relationship between magnitude (log energy) and log frequency of earthquakes is well known ${ }^{7}$. I have plotted data supplied by the Swiss Earthquake Service ${ }^{8}$. Millions of earthquakes have occurred since registering began early this century. These earthquakes could be classified on the basis of their magnitude. The data show a perfect linear correlation on a log-log plot (Fig. 1).

Had the statistical analysis of earthquakes been based upon only the few large earthquakes that caused catastrophic damage, the quantitative relationship between magnitude and frequency could hardly have been established. The key to the prediction of reactor catastrophes may thus be to use the data of smaller accidents - what have been called operational disturbances and shutdowns, which are frequently reported by the news media.

The mathematical relationship between the frequency $F$ and the magnitude $M$ caused by incidents should have the general form

and is

$$
F=f(1 / M)
$$

$$
\log F=-k \log M+C
$$

if it is an inverse $\log / \log$ relationship like that for earthquakes, where $k$ is the slope of the line, and $C$ is the intercept.

The parameter $F$ is easy to define. Incidents and accidents can be classified into different classes on the basis of their magnitude. The frequency of occurrence of each class can be computed on a factoryyear or factory-hour basis.

Several parameters could be chosen to express the magnitude of the accident. One is to use the radioactivity released. But whereas large accidents release a significant amount of radioactivity, smaller incidents may release none, so to use radioactivity release would exclude many small incidents from statistical analyses. Also the amount of radioactive release at Chernobyl is near the upper end of the spectrum; one cannot expect a substantial $\log / \log$ linear extrapolation of the frequency-magnitude relation far beyond that of Chernobyl.

One useful parameter for measuring natural or man-made catastrophes is a monetary unit. I suggest that we use Swiss francs, a most stable currency, as the parameter $M$ in the frequency-magnitude plot. The usual methods of relating finan-

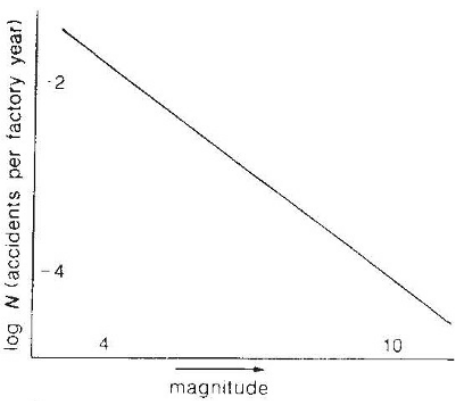

Fig 2 Nuclear safety plot, suggested relation. Frequency in log factory years, and magnitude in log swiss francs.

cial losses to incidents and accidents can be used to calculate $M$. For the smallest incidents, the financial losses may involve only the monetary equivalent of the electricity not produced while the plant is shut down. For small incidents involving minimal radioactivity, additional damage because of the prospect of future cancer deaths should be considered. For a big accident, like Three Mile Island, the very large expenses of dealing with or disposing of a damaged reactor have to be added. For very big accidents, like Chernobyl, there are additional costs, including the 'cost' of actual deaths (to be estimated on the basis of insurance premiums or of damage payment in law suits), damages to property and to agricultural products, genetic damage to unborn children and the values of land and properties that become unusable because of the contamination by radioactivity. The last of these is very important: the monetary value of Swiss properties, for example, is such that an accident releasing the same amount of radioactivity to Swiss towns and villages as that released around Chernobyl would be at least 10 and perhaps even 1,000 times more expensive than it was. We are far from having reached the upper end of the spectrum if the environmental cost is measured in financial terms.

My preliminary impression, judged on the basis of the frequency of shutdowns and the two large accidents, is that the relationship may take the form shown by Fig. 2. A more exact relationship will depend upon the evaluation of data now being requested from nuclear regulating agencies.

\section{Geologisches Institut,}

KeNNETH Hsü

\section{ETH-Zentrum}

CH-8092, Zurich,

Switzerland

Reactor Safety Study (Nuclear Regulatory Comm. Washing ton DC. 1975)

Wilson, R. Nature 323, 29-30 (1986)

Islam. S. \& Lindgren, K. Nature 322, 691 (1986)

Tiedemann, H. Nature 324, 404 (1986)

5. Hsü, K. J. Sedimentology 30, 3 (1983)

6. Shoemaker. E.M. A. Rev. Earth planet Sci. 11, 461 (1983).

. Gutenburg, B. \& Richter. C.F. Seismicity of the Earth and Associated Phenomena (Princeton Univ. Press, 1949).

Erdbeben, Entstehung, Risika und Hilfe (Schweizerische Geophysikalische Kommission, Zurich, 1986) 